\title{
Methodological aspects of the study of seismic sequences by SDP (self-developing processes) on the example of the Nevel'sk earthquake on Sakhalin
}

\author{
Alexander S. Zakupin* \\ Natalia V. Boginskaya \\ Mariya Yu. Andreeva
}

\author{
Institute of Marine Geology and Geophysics FEB RAS, \\ Yuzhno-Sakhalinsk, Russia \\ *E-mail:a.zakupin@imgg.ru
}

\begin{abstract}
Peфepat PDF Rus
The features of the application of the method of analysis of foreshock sequences of SDP (selfdeveloping processes) in the Sakhalin region are discussed. On the example of the Nevel'sk earthquake (2007, $M=6.2$ ), the characteristics of activations preceding the main shock were estimated by the areal scanning method. A universal approach for seismic hazard assessment by SDP method is proposed. Calculations are made for the catalogue of weak earthquakes with magnitudes $\mathrm{M} \leq 3$ and for the complete catalogue of seismic events without restrictions on magnitude, the advantage of sampling weak events is shown. A significant influence on the result was exerted by the declustering, which reduced the effect of aftershocks of the earthquake preceding Nevel'sk. The connection of the SDP sequences with the development of the focal area and the appearance of abnormal values of LURR (load-unload response ratio) parameter is established. A number of features are obtained, according to which in real time it is possible to allocate the place and time (up to weeks) of the main event.
\end{abstract}

\section{Keywords}

seismicity, seismic events, LURR method, earthquakes catalog, fault, prediction

For citation: Zakupin A.S., Boginskaya N.V., Andreeva M.Yu. Methodological aspects of the study of aftershock sequences by SDP (self-developing processes) on the example of the Nevel'sk earthquake on Sakhalin. Geosystems of Transition Zones, 2019, vol. 3, no. 4, pp. 377-389. (In Russian) https://doi.org/10.30730/25418912.2019.3.4.377-389

Для цитирования: Закупин А.С., Богинская Н.В., Андреева М.Ю. Методические аспекты исследования форшоковых последовательностей методом СРП (саморазвивающиеся процессы) на примере Невельского землетрясения на Сахалине. Геосистемы переходных зон. 2019. Т. 3, № 4. С. 377-389.

https://doi.org/10.30730/2541-8912.2019.3.4.377-389

\section{References}

1. Завьялов А.Д. Среднесрочный прогноз землетрясений: основы, методика, реализаџия. М.: Наука, 2006. $254 \mathrm{c}$.

2. Закупин А.С. Программный комплекс для анализа неустойчивости сейсмического процесса // Геоинформатика. 2016. № 1. С. 34-43.

3. Закупин А.С., Левин Ю.Н., Богинская Н.В., Жердева О.А. Развитие методов среднесрочного прогноза на примере Онорского землетрясения на Сахалине (Mw=5.8, 14 августа 2016 года) // Геология и геофизика. 2018. T. 59, № 11. С. 1904-1911. doi:10.15372/GiG20181112 [Zakupin A.S., Levin Yu.N., Boginskaya N.V., Zherdeva O.A. Development of medium-term prediction methods: A case study of the August 14, 2016 Onor ( $\mathrm{Mw}=5.8)$ earthquake on Sakhalin. Russian Geology and Geophysics. 59(11): 1526-1532. https://doi.org/10.1016/j.rgg.2018.10.012] 
4. Зубков С.И. Предвестники землетрясений. М.: ОИФЗ РАН, 2002. 140 с.

5. Левин Б.В., Ким Ч.У., Соловьев В.Н. Оценка сейсмической опасности и результаты детального сейсмического районирования для городов о. Сахалин = Levin B.V., Chun Un Kim, Solovjev V.N. Seismic hazard estimate and results of detailed seismic zoning for the cities of Sakhalin Island // Тихоокеанская геология. 2012. Т. 31, № 5. С. 93-103.

6. Малышев А.И. Динамика саморазвивающихся процессов // Вулканология и сейсмология. 1991. № 4. C. $61-72$.

7. Малышев А.И. Прогнозируемость сейсмического потока и сильных землетрясений Камчатки в 1962-2014 гг. Вулканология и сейсмология. 2019. № 1. С. 52-66. [Malyshev A.I. The predictability of seismicity and large earthquakes: Kamchatka 1962 to 2014. J. of Volcanology and Seismology. 2019, 13(1): 42-55]. https://doi.org/10.31857/s0205-96142019152-66

8. Малышев А.И., Малышева Л.К. Прогнозируемость потока сейсмической энергии северо-западного обрамления Тихого океана по данным каталога USGS = Malyshev A.I., Malysheva L.K. Predictability of seismic energy rate in northwest frame of Pacific Ocean on the base of USGS catalogue // Геосистемь переходных зон $=$ Geosystems of Transition Zones. 2018. T. 2, № 3. C. 141-153. doi.org/10.30730/25418912.2018.2.3.141-153

9. Малышев А.И., Тихонов И.Н. Нелинейные закономерности развития сейсмического процесса во времени // Физика Земли. 2007. № 6. С. 37-51.

10. Матвиенко Ю.Д. Применение методики М8 на Камчатке: успешный заблаговременный прогноз землетрясения 5 декабря 1997 г. // Вулканология и сейсмология. 1998. № 6. С. 27-36.

11. Молчан Г.М.. Дмитриева О.Е. Целевой подход к проблеме идентификации афтершоков // Сейсмичность и сейсмическое районирование Северной Евразии. М.: ОИФЗ РАН, 1993. Вып. 1. C. 62-69.

12. Рождественский В.С., Сапрыгин С.М. Активные разломы и сейсмичность на Южном Сахалине // Тихоокеанская геология. 1999. № 6. С. 59-70.

13. Смирнов В.Б. Опыт оценки представительности данных каталогов землетрясений // Вулканология $u$ сейсмология. 1997. № 4. С. 93-105.

14. Соболев Г.А. Стадии подготовки сильных камчатских землетрясений // Вулканология и сейсмология. 1999. № 4-5. С. 63-72.

15. Тихонов И.Н. Методы анализа каталогов землетрясений для целей средне- и краткосрочного прогнозов сильных сейсмических событий. Южно-Сахалинск: ИМГиГ ДВО РАН, 2006. 214 с.

16. Тихонов И.Н. Прогноз сильного землетрясения на юго-западном шельфе острова Сахалин и его реализация в результате Невельского землетрясения 2 августа 2007 года // Тихоокеанская геология. 2009. T. 28, № 5. C. 22-29.

17. Тихонов И.Н., Ким Ч.У. Успешный прогноз Невельского землетрясения 2 августа 2007 г. (MLH = 6.2) на юге о-ва Сахалин // Доклады Академии наук. 2008. Т. 420, № 4. С. 532-536.

18. Тихонов И.Н., Левин Б.В. Прогноз сильных землетрясений Сахалинской области: история, результаты и перспективы // Геодинамические прочессы и природные катастрофы. Onыт Нефтегорска: Всерос. науч. конф. с международным участием, 26-31 мая 2015, Южно-Сахалинск. Владивосток: Дальнаука, 2015. С. 41-45.

19. Тихонов И.Н., Михайлов В.И., Малышев А.И. Моделирование последовательностей землетрясений юга Сахалина, предваряющих сильные толчки, с целью краткосрочного прогноза времени их возникновения // Тихоокеанская геология. 2017. Т. 36, № 1. С. 5-14. [Tikhonov I.N., Mikhaylov V.I., Malyshev A.I. Modeling the Southern Sakhalin earthquake sequences preceding strong shocks for shortterm prediction of their origin time. Russian J. of Pacific Geology, 2017, 11(1): 1-10. https://doi.org/10.1134/s1819714017010092]

20. Харахинов В.В. Нефтегазовая геология Сахалинского региона. М.: Научный мир, 2010. 275 с.

21. Arellano-Baeza A.A., Zverev A.T., Malinnikov V.A. Study of changes in the leniament structure? Caused by earthquakes in South America by applying the leniament analysis to the Aster (Terra) satellite data // Advances in Space Research. 2006. Vol. 37. P. 690-697. https://doi.org/10.1016/j.asr.2005.07.068

22. Geller R.J. Earthquake prediction: A critical review // Geophysical J. International. 1997. Vol. 131(3). P. 425-450. https://doi.org/10.1111/j.1365-246x.1997.tb06588.x

23. Geller R.J., Jackson D.D., Kagan Y.Y., Mulargia F. Earthquakes cannot be predicted // Science. 1997. Vol. 275(5306). P. 1616-1619. https://doi.org/10.1126/science.275.5306.1616

24. Hamilton R.M. The President's Page: Earthquake prediction and public reaction [Guest Editorial] // EOS, Transactions American Geophysical Union. 1974. Vol. 55(8). P. 739-742. https://doi.org/10.1029/eo055i008p00739

25. Kagan Y. Seismic moment-frequency relation for shallow earthquakes: Regional comparison // J. Geophysical Research: Solid Earth. 1997. Vol. 102(B2). P. 2835-2852. https://doi.org/10.1029/96jb03386

26. Swinbanks D. Trying to shake Japan's faith in forecasts // Nature. 1992. Vol. 356. P. 464-465. https://doi.org/10.1038/356464a0 
27. Tikhonov I.N., Kim Ch.U. Confirmed prediction of the 2 August 2007 Mw 6.2 Nevelsk earthquake (Sakhalin Island, Russia) // Tectonophysics. 2010. Vol. 485 (1-4). P. 85-93. https://doi.org/10.1016/j.tecto.2009.12.002

28. Tikhonov I.N., Rodkin M.V. Earthquake research and analysis // Sebastiano D'Amico, Dr (ed.). Statistical Studies, Observations and Planning. Malta: Univ. of Malta, 2012. P. 43-78.

29. Wyss M. Cannot earthquakes be predicted? // Science. 1997. Vol. 278(5337). P. 487-488. https://doi.org/10.1126/science.278.5337.487

30. Wang K., Chen Qi-Fu, Sun Shihong, Wang Andong. Predicting the 1975 Haicheng Earthquake // Bulletin of the Seismological Society of America. 2006. Vol. 96(3). P. 757-795. https://doi.org/10.1785/0120050191

31. Zhang G., Fu Z. Some features of medium and short-term anomalies before great earthquake // Earthquake Prediction: An International Review. 1981. P. 497-509. (Maurice Ewing Series; vol. 4). https://doi.org/10.1029/me004p0497 